\title{
Control of a utility connected microgrid
}

\author{
Alba Colet-Subirachs, Albert Ruiz-Alvarez, Oriol Gomis-Bellmunt, Felipe Alvarez-Cuevas-Figuerola, \\ Antoni Sudria-Andreu
}

\begin{abstract}
This paper describes the control algorithm of a utility connected microgrid, based on independent control of active and reactive power ( $P Q$ control) and working in centralized operation mode. The microgrid under investigation is composed of three configurable units: a generation unit, a storage unit and a load. These units are interfaced with the microgrid through a Voltage Source Converter (VSC) and are controlled by the nodes of the communication system by means of IEC 61850. A set of tests have been conducted to evaluate the microgrid behavior.
\end{abstract}

Index Terms-Microgrid, control algorithm, IEC 61850.

\begin{tabular}{|c|c|c|c|}
\hline & NOMENCLATURE & & \\
\hline & Acronyms & & \\
\hline CHP & Combined Heat and Power & & \\
\hline RTC & Real Time Clock & & \\
\hline SoC & State of Charge & & \\
\hline VSC & Voltage Source Converter & & \\
\hline & Subscript & & Superscripts \\
\hline$i$ & Number of iSocket & * & Set point \\
\hline$M$ & Maximun & & \\
\hline$m$ & Minimun & & \\
\hline$p$ & Active power & & \\
\hline$q$ & Reactive power & & \\
\hline
\end{tabular}

\section{INTRODUCTION}

$\mathbf{T}$ HE need for more reliable and flexible power systems along with the tremendous potential of modern control and communication systems and power electronics, has led to development of the smart grid concept [1]-[3]. Modern grids will be required to be active and to adapt to a number of fault events ensuring the system optimum performance during and after faults occur [4], [5]. Furthermore, modern grids will have to integrate the increasing penetration of renewable energy of intermittent nature. This can be achieved using more flexible power systems including power electronics, energy storage systems, demand side management and microgrids.

A microgrid is defined as an aggregator of several microgeneration units, storage devices and controllable loads operating as a single system that provides electricity and

A. Colet-Subirachs, A. Ruiz-Alvarez, O. Gomis-Bellmunt and A. SudriàAndreu are with Catalonia Institute for Energy Research (IREC), Electrical Engineering Area, C Josep Pla, 2, edifici B2, Planta Baixa - 08019 Barcelona, Spain (e-mail: acolet@irec.cat, aruiz@irec.cat, ogomis@irec.cat, asudria@irec.cat)

O. Gomis-Bellmunt and A. Sudrià-Andreu are with Centre d'Innovació Tecnològica en Convertidors Estàtics i Accionaments (CITCEA-UPC), Departament d'Enginyeria Elèctrica, Universitat Politècnica de Catalunya, ETS d'Enginyeria Industrial de Barcelona, and EU d'Enginyeria Tècnica Industrial de Barcelona, Barcelona - 08028, Spain (e-mail: gomis@citcea.upc.edu, antoni.sudria@citcea.upc.edu)

F. Alvarez-Cuevas-Figuerola is with Endesa Servicios.sl, Av Paral-lel, 51 08004 Barcelona, Spain (e-mail: felipe.alvarezcuevas@endesa.es) thermal energy, i.e. combined heat and power (CHP) [6]-[8]. Microgrid is a concept that incorporates distributed energy resources (DER), including distributed generation (DG) and distributed storage (DS). To manage the DER, a network of communication devices must provide the microgrid with the necessary intelligence to allow customers and utility companies to collaboratively manage power generated, delivered, and consumed through real-time, bidirectional communications. Thus, communication is essential in order to ensure the proper operation of all the microgrid components [9]. Protection devices, control commands and power flow regulation, together with real-time measurements must be integrated in a hierarchical network to provide the necessary levels of quality and reliability to the microgrid.

A control strategy must be devised in such communication architecture in order to ensure the long-term stable operation of the microgrid under various load conditions and different configurations. Therefore there is a need to develop control algorithms defining the optimal set point for each DER [10][12]. The present paper presents the design, simulation and experimental results of a control algorithm implemented in an emulated microgrid.

\section{MicRogrid CONCEPT}

The Catalonia Institute for Energy Research (IREC) is currently developing a microgrid based on real and emulated energy resources in order to evaluate different scenarios [13]. This paper describes a part of such microgrid that is also involved in the Smartcity project located in Malaga (south of Spain) and managed by Endesa, the local utility.

The Malaga Smartcity project is a demonstration project in which it is intended to deploy and integrate the following items in the current grid:

- A highly reliable and efficient Broadband Power Line communications framework.

- Micro generation and micro storage within the lowvoltage grid.

- Mini generation and mini storage within the mediumvoltage grid.

- A small fleet of bi-directional electrical vehicles.

- A new and efficient street lighting system.

- A few thousands of smart meters.

- Improved grid self healing automation.

Fig. 1 shows the overview of the smart city envisioned. The communication architecture of such city is composed by an hierarchical layer system. The bottom layers are embodied by these two elements: 


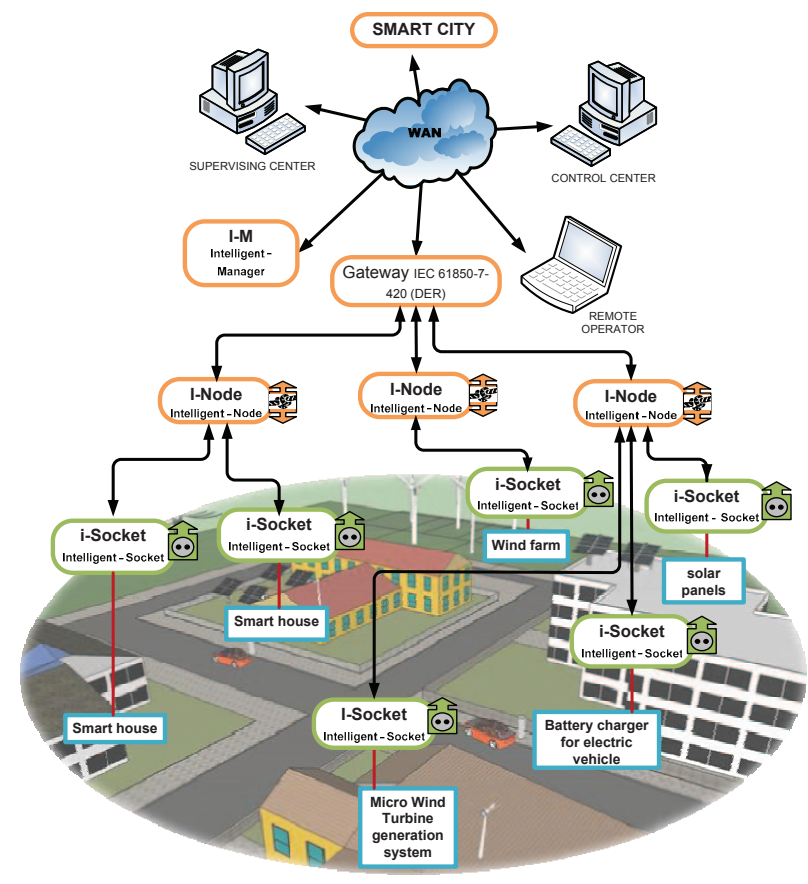

Fig. 1. Smart city functional block description

iNode (Intelligent Node): Develops the global management of microgrid tasks and connects supervising and control systems (through a Gateway) to the terminal equipment (iSocket). Its functions are managing the data received from iSockets and setting overall operation of the microgrid, developing its own algorithms. Its main tasks include:

- Regulation: Control of energy generation and consuming entities.

- Billing: Energy measurement and real-time pricing.

- Management: Asset management and condition basedmaintenance.

- Metering: full system monitoring.

- Security of the microgrid electrical system

The operational requests of this controller are: aggregation and coordination of iSockets and electrical safety guarantee.

iSocket (Intelligent Socket): It is an element located in the lowest hierarchy layer of the communication system. It handles the device connected to it (generation, storage or loading), based on the instructions received from the iNode. The operational requests of this controller are: local regulation and electrical safety guarantee.

\section{CONTROL Algorithm}

This paper proposes implementing a control algorithm with the capability to achieve the system goals using the available units, interfaced to the microgrid through a voltage-source converter (VSC). The control algorithm is based on independent control of active and reactive power in grid connected mode (PQ control) and it is working in a centralized operation mode. This operation mode suggests that a central node, iNode, collects the microgrid measurements (sent from iSockets) and decides next actions according to the utility goals. The iNode develops functions as purchasing and selling electricity to the grid, assuming that the iSockets cannot bid directly in the energy market.

To analyze the control algorithm it is important to take into consideration the sign criteria used in this paper (1):

$$
\left\{\begin{array} { l } 
{ P < 0 \rightarrow \text { Generation } } \\
{ P > 0 \rightarrow \text { Consumption } }
\end{array} \quad \left\{\begin{array}{l}
Q<0 \rightarrow \text { Capacitive } \\
Q>0 \rightarrow \text { Inductive }
\end{array}\right.\right.
$$

\section{A. iNode controller}

The iNode uses two independent PI controllers (Fig. 2), which are responsible for controlling the whole active and reactive power flux of the microgrid.

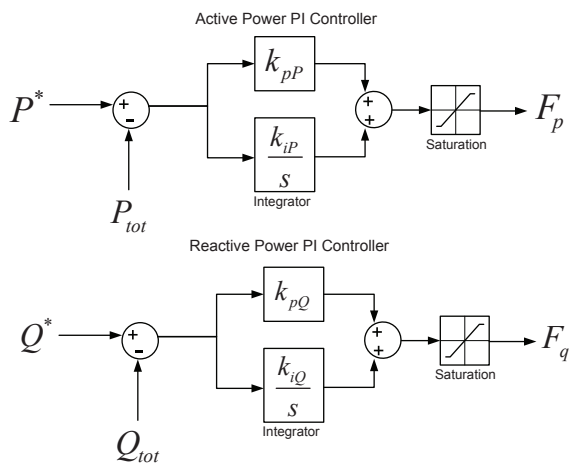

Fig. 2. iNode PI controller

According to Fig. 3, the iNode has the following inputs:

$P^{*}$ [W], $Q^{*}$ [VAr] the active and reactive power set points from the utility transferred in accordance with necessity of the microgrid system,

$P_{t o t}[\mathrm{~W}], Q_{t o t}[\mathrm{VAr}]$ the total active and reactive measurements which can be obtained as a direct value provided by the metering system or as a calculated value using the power sent by each iSocket, i.e, the sum of all active and reactive power of the connected iSockets (2):

$$
\begin{aligned}
P_{t o t} & =\sum_{i=1}^{n} P_{i} \\
Q_{t o t} & =\sum_{i=1}^{n} Q_{i}
\end{aligned}
$$

where $P_{i}$ and $Q_{i}$ are the active and reactive power of the iSocket number $i$.

$e \quad$ the current price of energy transferred from the utility $[\mathrm{c} \in / \mathrm{kWh}]$.

The iNode outputs are:

$F_{p} \quad$ active power control signal and

$F_{q} \quad$ reactive power control signal, where $-100 \leqslant F_{p} \leqslant 100$ and $-100 \leqslant F_{q} \leqslant 100$.

\section{B. iSocket controllers}

iSocket receive the control signals $F_{p}$ and $F_{q}$ and apply equations (3) and (4) to calculate the active and reactive 


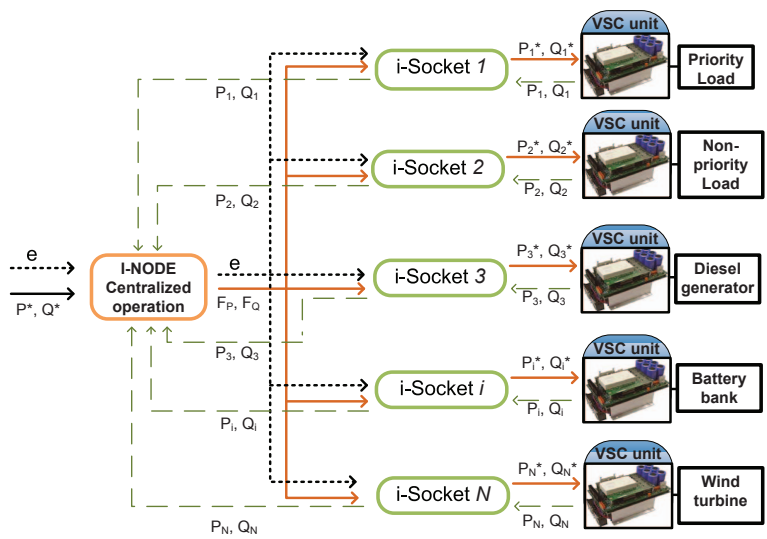

Fig. 3. Centralized operation block description

power to set $\left(P_{i}^{*}, Q_{i}^{*}\right)$ to the VSC connected to them.

$$
\begin{aligned}
& P_{i}^{*}=\left\{\begin{array}{lc}
P_{i, M} & \beta_{p i}<F_{p} \\
P_{i, m}+\left(P_{i, M}-P_{i, m}\right) \frac{F_{p}-\alpha_{p i}}{\beta_{p i}-\alpha_{p i}} & \beta_{p i} \geq F_{p} \geq \alpha_{p i} \\
P_{i, m} & \alpha_{P i}>F_{p}
\end{array}\right. \\
& \text { with } \beta_{p i} \geqslant \alpha_{p i} \\
& Q_{i}^{*}=\left\{\begin{array}{lr}
Q_{i, M} & \beta_{q i}<F_{q} \quad \text { (4a) } \\
Q_{i, m}+\left(Q_{i, M}-Q_{i, m}\right) \frac{F_{q}-\alpha_{q i}}{\beta_{q i}-\alpha_{q i}} & \beta_{q i} \geq F_{q} \geq \alpha_{q i} \text { (4b) } \\
Q_{i, m} & \alpha_{q i}>F_{q} \quad \text { (4c) }
\end{array}\right.
\end{aligned}
$$$$
\text { with } \beta_{q i} \geqslant \alpha_{q i}
$$

These equations are piecewise-defined functions divided into different sections depending on the power profile to be set to each microgrid unit. However, this paper considers a power profile divided into three sections (Fig. 4): the firsts equations $(3 \mathrm{a}, 4 \mathrm{a})$ correspond to the maximum power to be set $\left(P_{i, M}, Q_{i, M}\right)$, the second section $(3 \mathrm{~b}, 4 \mathrm{~b})$ is a ramp between maximum and minimum power, and the third (3c, $4 \mathrm{c})$ corresponds to the minimum value $\left(P_{i, m}, Q_{i, m}\right)$.
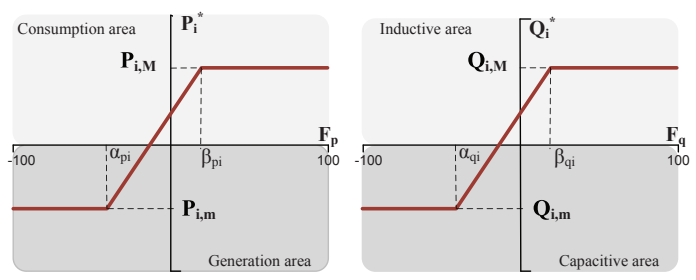

Fig. 4. General power profile functions set by the iSocket

The parameters $\alpha$ and $\beta$, configured at each iSocket, are used to define the power limits and the participation priorities of the microgrid units. Its value is recalculated dynamically: as there is a change in the state of a microgrid unit, the iSocket interfaced with it perceives this variation, and modifies $\alpha$ and $\beta$. Also, these parameters are recalculated according to variables such as the energy price.

Depending on the type of microgrid unit, iSockets are divided into three main cases:
1) Generation iSockets: A generation node $i$ will be characterized by:

$$
\left\{\begin{array} { l } 
{ \alpha _ { p i } = \alpha _ { p i 0 } - k _ { E } e _ { i , c } + k _ { p } \cdot e } \\
{ \beta _ { p i } = \beta _ { p i 0 } - k _ { E } e _ { i , c } + k _ { p } \cdot e }
\end{array} \quad \left\{\begin{array}{c}
\alpha_{q i}=\alpha_{q i 0} \\
\beta_{q i}=\beta_{q i 0}
\end{array}\right.\right.
$$

Where

$\alpha_{p i 0}, \beta_{p i 0}, \alpha_{q i 0}, \beta_{q i 0}$ are selectable parameters used to prioritize each power generation source,

$e_{i, c}$ is the generation cost $[\mathrm{c} \in / \mathrm{kWh}]$,

$k_{E}$ is a multiplier of the generation cost and

$k_{p}$ is a multiplier of the energy cost.

2) Storage iSockets: A storage node $i$ will be characterized by:

$$
\begin{gathered}
\left\{\begin{array}{l}
\alpha_{p i}=\alpha_{p i 0}-k_{w} W_{i, a}+k_{p} e \\
\beta_{p i}=\beta_{p i 0}-k_{w}\left(W_{i, M}-W_{i, a}\right)+k_{p} e
\end{array}\right. \\
\left\{\begin{array}{l}
\alpha_{q i}=\alpha_{q i 0} \\
\beta_{q i}=\beta_{q i 0}
\end{array}\right.
\end{gathered}
$$

Where

$W_{i, M}$ is the maximum storable energy $(100 \%)$

$W_{i, a}$ is the available energy (0-100\%) and

$k_{w} \quad$ is a multiplier of the available energy.

3) Load iSockets:

$$
\left\{\begin{array} { l } 
{ \alpha _ { p i } = \alpha _ { p i 0 } - k _ { r } e _ { i , c r c } + k _ { p } e } \\
{ \beta _ { p i } = \beta _ { p i 0 } - k _ { r } e _ { i , c r c } + k _ { p } e }
\end{array} \quad \left\{\begin{array}{l}
\alpha_{q i}=\alpha_{q i 0} \\
\beta_{q i}=\beta_{q i 0}
\end{array}\right.\right.
$$

Where

$e_{i, c r c}$ is the cost of load reduction [c $\left.€ / \mathrm{kWh}\right]$ and

$k_{r} \quad$ is a multiplier of the load reduction cost.

\section{SYSTEM DESCRIPTION}

The microgrid experimental platform under investigation (Fig. 5) is composed of two main systems: the communication system and the power system. The communication system is based on a remote monitoring and control system for the power system.

\section{A. Power system description}

The microgrid power system is composed of a three configurable units:

- Generation unit: emulates different types of generation such as wind and solar, reproducing the real behavior, and in the case of renewable energy sources, reproducing the variable nature and dependence on external climatological factors.

- Load unit: emulates the real behavior of different types of consumption based on sensitive-loads and/or nonsensitive-loads using various load profiles.

- Energy storage unit: emulates a storage system which, according to the needs, can be either a battery or an electric vehicle.

The use of these configurable units (shown in Fig. 6) allows the emulation of scenarios that are deemed of interest 


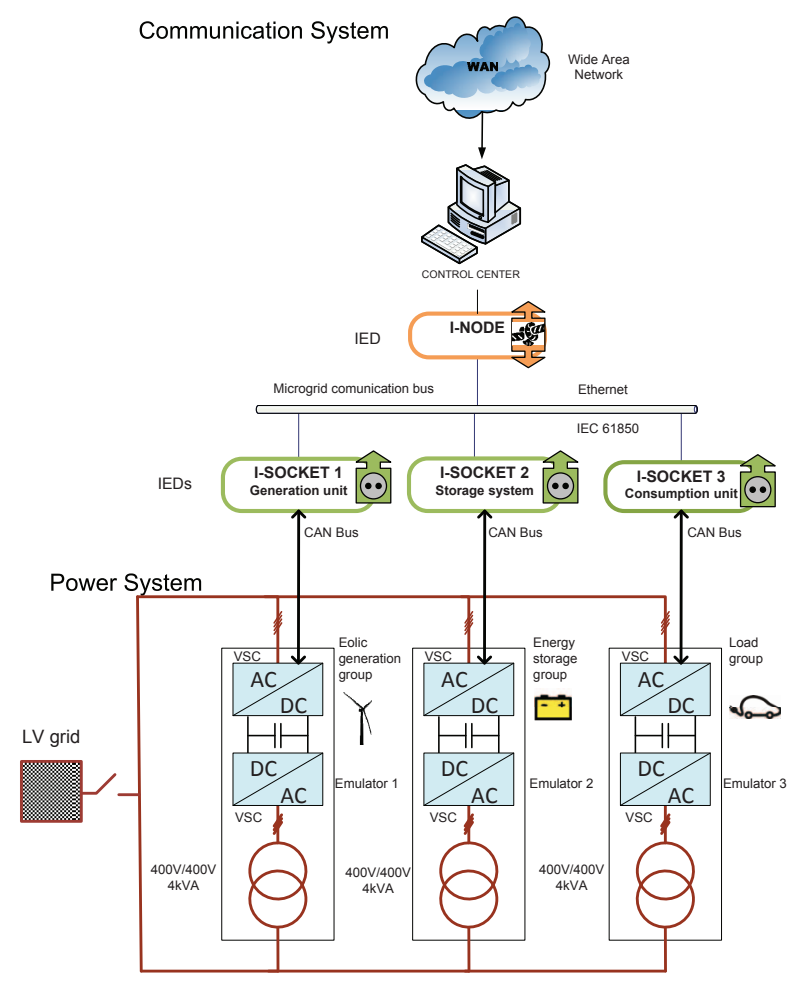

Fig. 5. Microgrid functional block description

without having to wait for appropriate weather conditions. The configurability property of them allows the emulation of any situation generating or consuming real power.

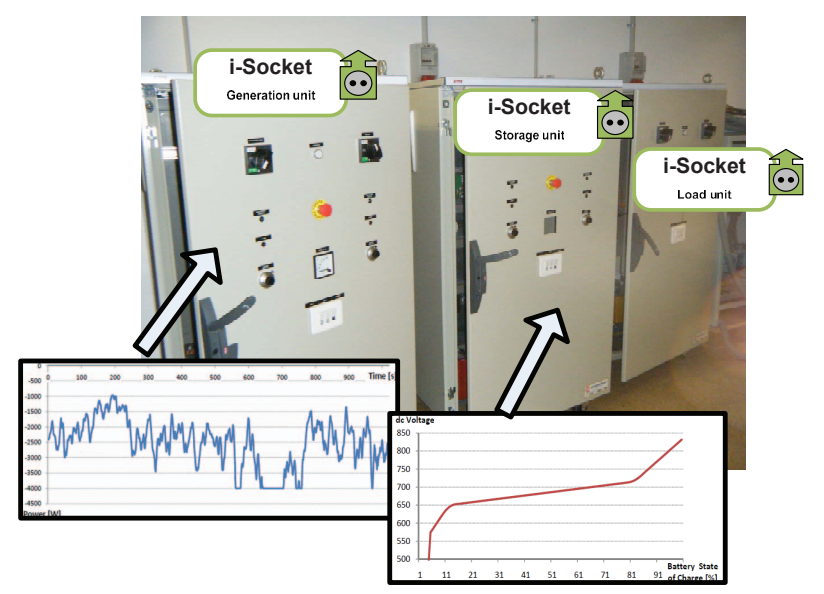

Fig. 6. Microgrid power units configuration

Each unit of the microgrid power system has two VSC composed of a three-phase inverter, AC and DC transducers and protective devices. Its design enables utilization as a configurable renewable generation emulator, a battery bank or a load. The converters are connected in a back to back configuration, so while one acts like a bidirectional boostrectifier, the other one transfers power to the grid according to the set point given by the communication node iSocket [14]. Therefore, there is a power flow through these devices in which only converter losses are consumed.

\section{B. Communication system description}

The communication system is composed of four nodes: one iNode and three iSockets. Each node is implemented in a Linux embedded control board. Depending on the communication layer, a different communication protocol is used:

- Communication between iNode and iSocket is done with standard IEC 61850 [15]-[17].

- Communication between the iSocket and its appropriate VSC uses a CAN proprietary protocol. The iSocket transmits a data frame that contains a command word, a $P_{i}^{*}$ and $Q_{i}^{*}$ to be set to the VSC. The VSC answers with three CAN messages, which contain the status of the unit and other information such as $P_{i}$ and $Q_{i}$.

Data exchange between iNode and iSockets will be monitored in a IEC 61850 SCADA (Fig. 7).

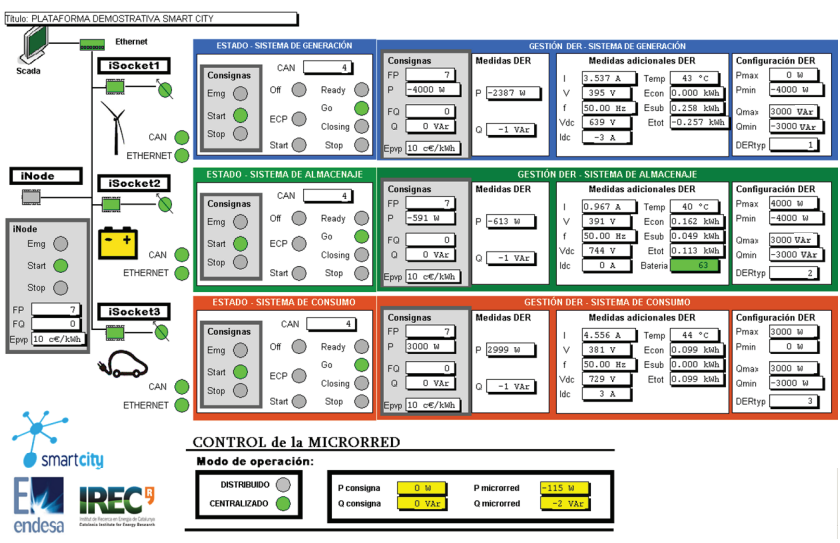

Fig. 7. Microgrid IEC 61850 SCADA

\section{EXPERIMENTAL RESULTS}

On the basis of the previously described experimental system, experimental test were performed. To develop these tests, the microgrid units are configured to emulate a dispatching load (managed by iSocket3), a battery (managed by iSocket2) and a micro wind turbine (managed by iSocket1). The battery is characterized by a $\mathrm{Ni}-\mathrm{Cd}$ model described in Table I.

However, to study changes in the battery $\mathrm{SoC}$ during testing, its capacity has been reduced to $1 \mathrm{~A} / \mathrm{h}$. The wind power curve implemented in the wind turbine emulator is shown in Table II.

To ensure the proper operation of the proposed control algorithm, it must be defined the set of instructions that each iSocket applies to its corresponding microgrid unit. These instructions are specified by the parameters listed in Table III. Replacing it in the equations (2-7), the resulting functions can be seen in Table IV. 
TABLE I

CONFIGURATION CHARACTERISTICS OF THE BATTERY EMULATOR

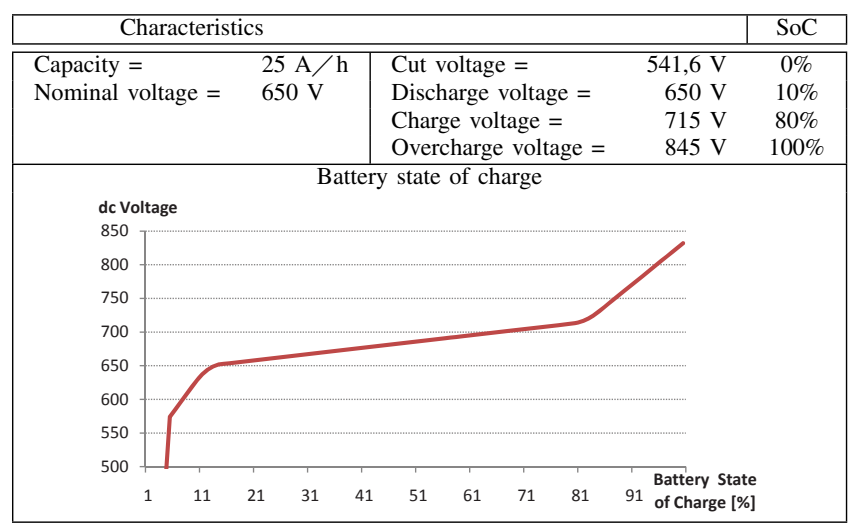

TABLE II

CONFIGURATION CHARACTERISTICS OF THE WIND TURBINE EMULATOR

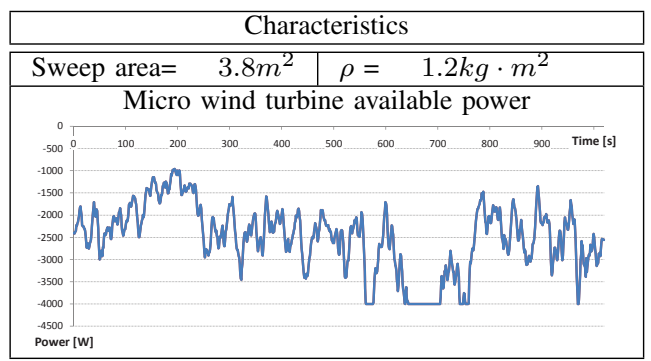

TABLE III

MICROGRID TEST PARAMETERS

\begin{tabular}{|l||ccc|}
\hline Parameters & iSocket1 & iSocket2 & iSocket3 \\
\hline \hline$P_{i, m}$ [W] & -4000 & -4000 & 0 \\
$P_{i, M}$ [W] & 0 & 4000 & 3000 \\
$Q_{i, m}$ [VAr] & -3000 & -3000 & -3000 \\
$Q_{i, M}$ [VAr] & 3000 & 3000 & 3000 \\
\hline$\alpha_{P i 0}$ & 40 & -180 & -100 \\
$\beta_{P i 0}$ & 80 & 60 & -30 \\
$\alpha_{Q i 0}$ & -100 & -100 & -100 \\
$\beta_{Q i 0}$ & 100 & 100 & 100 \\
\hline$k_{p}$ & 0 & 6 & 2 \\
$k_{E}$ & 0 & - & - \\
$k_{w}$ & - & 1.2 & - \\
$k_{r}$ & - & - & 0 \\
\hline
\end{tabular}

To test the microgrid response, two case studies are considered: In the first the energy price is constant and in the second it changes.

\section{A. Case Study 1: constant energy price}

Fig. 8 shows system response with respect to changes to the microgrid power set point, $P^{*}$, for a fixed energy price, $e=10 \mathrm{c} € / \mathrm{kWh}$, during a time interval of 600 seconds. It is composed of five graphs: Battery SoC, Power, Active and Reactive total power, Control signals and Energy price.

The Power graph shows the evolution of the powers of each microgrid element. The power curves shape of the wind turbine and the battery has a mirror effect, since the battery compensates the wind power fluctuation.

The Active and Reactive total power graph contains the
TABLE IV

MICROGRID TEST FUNCTIONS

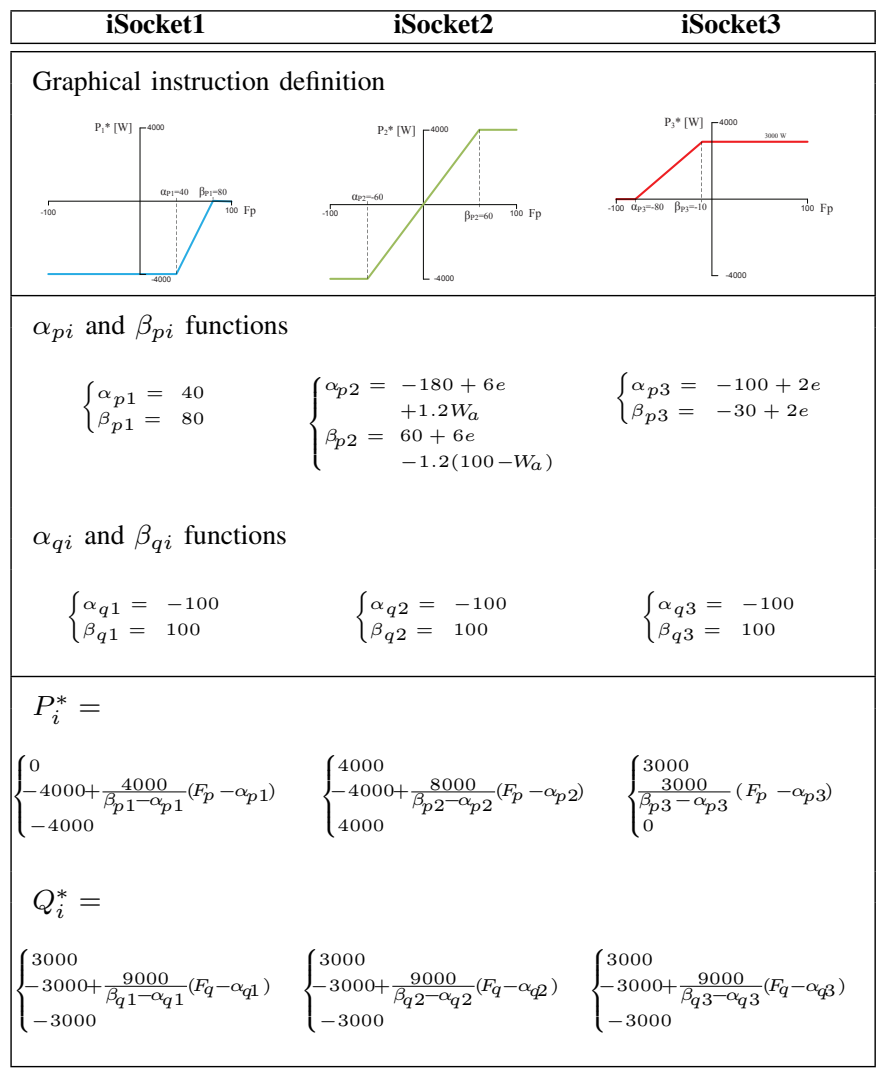

TABLE V

CENTRALIZED OPERATION MICROGRID RESPONSE

\begin{tabular}{|c||cc|}
\hline Interval & $P^{*}[\mathrm{~W}]$ & $Q^{*}[\mathrm{VAr}]$ \\
\hline \hline$t_{0} \mapsto t_{1}$ & 0 & 0 \\
\hline$t_{1} \mapsto t_{2}$ & 5000 & 0 \\
\hline$t_{2} \mapsto t_{3}$ & 3000 & 0 \\
\hline$t_{3} \mapsto t_{4}$ & 3000 & 0 \\
\hline$t_{4} \mapsto t_{5}$ & -4000 & 675 \\
\hline$t_{5} \mapsto t_{6}$ & -4000 & -350 \\
\hline$t_{6} \mapsto t_{7}$ & -1000 & 0 \\
\hline$t_{7} \mapsto$ & 1000 & 0 \\
\hline
\end{tabular}

microgrid global powers. It can be checked that the value corresponding to the active power, $P_{t o t}$, is in accordance with the set value, $P^{*}$.

Table $\mathrm{V}$ shows the reference power applied to the microgrid in centralized mode according Fig. 8. In the time interval $t_{0} \mapsto t_{1}$ the battery SoC remains stable at a $50 \%$ and the load is powered by the battery and the wind turbine. In the interval $t_{1} \mapsto t_{3}$, the microgrid consumes $P^{*}=5000$ to 3000W from the grid which supplies the load and charges the battery. As the SoC of the battery increases, it is more reluctant to charge. Thus, to keep $P^{*}$, the control signal $F_{p}$ should be more aggressive (it increases) and the power generated by the wind turbine is reduced. When the battery is fully charged, $t_{3} \mapsto t_{4}$, the unique consumption is the load and to maintain the $P^{*}$ set point, the wind turbine must disconnect. In the time interval $t_{4} \mapsto t_{5}$ the microgrid generates $4000 \mathrm{~W}$ by discharging the battery, reducing the load consumption and reconnecting the wind 


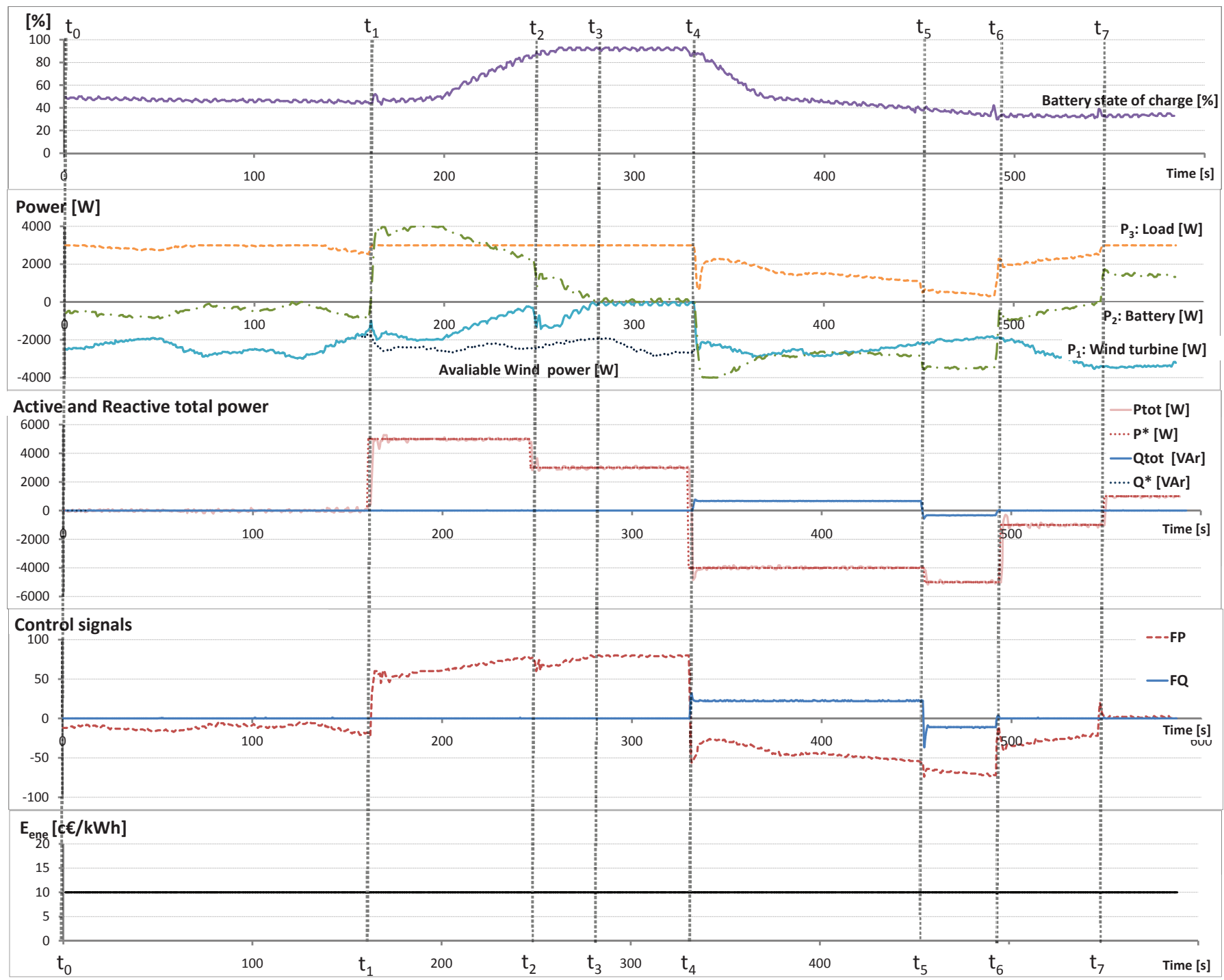

Fig. 8. Centralized operation Microgrid response (Case study 1)

turbine. The battery SoC steady drops to a $38 \%$. At $t_{4} \mapsto t_{5}$ there is an inductive compensation of the microgrid. Finally, in $t_{5} \mapsto t_{6}$ there is a capacitive compensation of the microgrid.

\section{B. Case Study 2: non-constant energy price}

To analyze the effect of energy price changes in the centralized operational mode, Fig. 9 and Table VI must be considered. In this case, the system reacts to the changes in energy price so that a new equilibrium point is established in order to keep the set value of global power. Therefore, there is a new scenario for the microgrid units. When the price increases, $t_{0} \mapsto t_{2}$ the battery $\left(P_{2}\right)$ fails to load.

\section{CONCLUSION}

This paper has presented a control algorithm implemented in a utility connected microgrid experimental platform. A controller has been defined for each node of the communication system of the microgrid. Furthermore, the control
TABLE VI

CENTRALIZED OPERATION MICROGRID RESPONSE UNDER A ENERGY PRICE CHANGE

\begin{tabular}{|l||cc|c|}
\hline Interval & $P^{*}[\mathrm{~W}]$ & $e[\mathrm{c} € / \mathrm{kWh}]$ & $F_{p}$ \\
\hline \hline$t_{0} \mapsto t_{1}$ & 1000 & 10 & {$[-10,12]$} \\
\hline$t_{1} \mapsto t_{2}$ & 1000 & 15 & {$[24,37]$} \\
\hline$t_{2} \mapsto$ & 1000 & 10 & {$[-10,0]$} \\
\hline
\end{tabular}

parameters have been adjusted to achieve the best possible system response.

The control algorithm, running in centralized operational mode, is evaluated experimentally based on system behavior in two case studies: constant energy price and non-constant energy price. From the analysis performed, the following main conclusions can be derived: the microgrid maintains the reference values given by a central node even when there is a change in the energy price, variable wind speed or disconnection of a microgrid unit. Storage devices help to supply demand in case of a lack of generation using when renewable energy resources. 


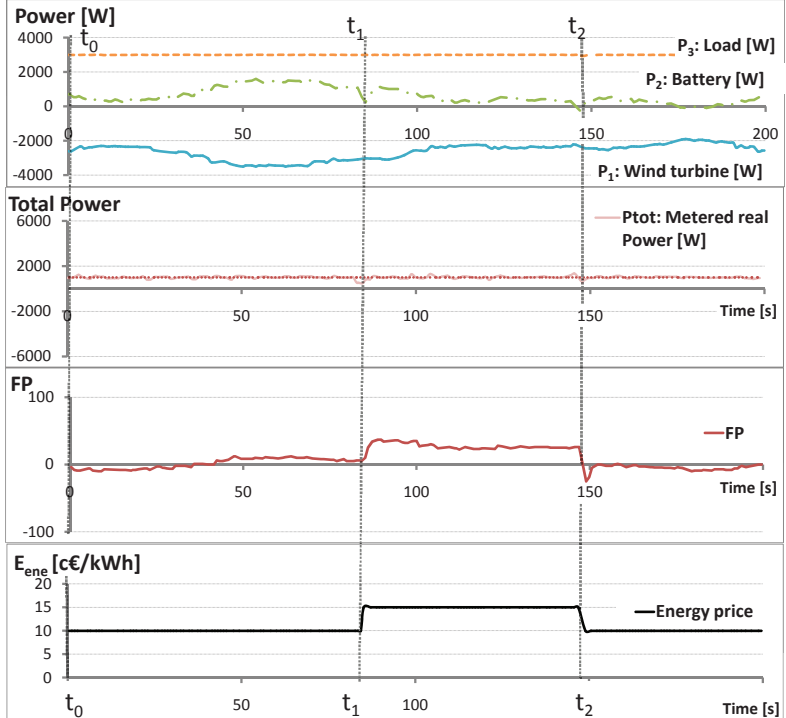

Fig. 9. Centralized operation microgrid response under a energy price change (Case study 2)

\section{ACKNOWLEDGMENT}

The authors especially appreciate the cooperation and support given by Cinergia.coop and would like to thank the contributions of J. M. Fenandez-Mola, M. Roman-Barri and R. Gumara-Ferret.

\section{REFERENCES}

[1] H. Farhangi, "The path of the smart grid," Power and Energy Magazine, IEEE, vol. 8, no. 1, pp. $18-28$, january-february 2010 .

[2] S. Karnouskos and T. de Holanda, "Simulation of a smart grid city with software agents," in Computer Modeling and Simulation, 2009. EMS '09. Third UKSim European Symposium on, 25-27 2009, pp. $424-429$.

[3] M. Hommelberg, C. Warmer, I. Kamphuis, J. Kok, and G. Schaeffer, "Distributed control concepts using multi-agent technology and automatic markets: An indispensable feature of smart power grids," in Power Engineering Society General Meeting, 2007. IEEE, 24-28 2007, pp. 1 $-7$.

[4] M. Prodanovic and T. Green, "High-quality power generation through distributed control of a power park microgrid," Industrial Electronics, IEEE Transactions on, vol. 53, no. 5, pp. 1471 -1482, oct. 2006.

[5] N. Pogaku, M. Prodanovic, and T. Green, "Modeling, analysis and testing of autonomous operation of an inverter-based microgrid," Power Electronics, IEEE Transactions on, vol. 22, no. 2, pp. 613 -625, march 2007.

[6] G. Venkataramanan and C. Marnay, "A larger role for microgrids," Power and Energy Magazine, IEEE, vol. 6, no. 3, pp. 78 -82, may-june 2008.

[7] B. Kroposki, R. Lasseter, T. Ise, S. Morozumi, S. Papatlianassiou, and N. Hatziargyriou, "Making microgrids work," Power and Energy Magazine, IEEE, vol. 6, no. 3, pp. 40 -53, may-june 2008.

[8] J. P. Lopes, S. A. Polenz, C. Moreira, and R. Cherkaoui, "Identification of control and management strategies for $1 \mathrm{v}$ unbalanced microgrids with plugged-in electric vehicles," Electric Power Systems Research, vol. 80, no. 8, pp. 898 - 906, 2010. [Online]. Available: http://www.sciencedirect.com/science/article/B6V304Y718XY-3/2/b2c39b33262d943a387e12a4cbaa1e7b

[9] U. Abdulwahid, J. Manwell, and J. Mcgowan, "Development of a dynamic control communication system for hybrid power systems," Renewable Power Generation, IET, vol. 1, no. 1, pp. $70-80$, march 2007.

[10] S.-J. Ahn, J.-W. Park, I.-Y. Chung, S.-I. Moon, S.-H. Kang, and S.R. Nam, "Power-sharing method of multiple distributed generators considering control modes and configurations of a microgrid," vol. 25, no. 3, pp. 2007-2016, 2010.
[11] A. Mehrizi-Sani and R. Iravani, "Potential-function based control of a microgrid in islanded and grid-connected modes," Power Systems, IEEE Transactions on, vol. PP, no. 99, pp. 1-1, 2010.

[12] J. Lopes, C. Moreira, and A. Madureira, "Defining control strategies for microgrids islanded operation," Power Systems, IEEE Transactions on, vol. 21 , no. 2 , pp. 916 - 924 , may 2006 .

[13] M. Roman-Barri, I. Cairo, A. Sumper, and A. Sudria, "Experience on the implementation of a microgrid project in barcelona," June 2010, iEEE ISGT Europe 2010, Gothenburg, Sweden, October 11-13, 2010.

[14] R. Majumder, A. Ghosh, G. Ledwich, and F. Zare, "Power management and power flow control with back-to-back converters in a utility connected microgrid," vol. 25 , no. 2, pp. 821-834, 2010.

[15] R. E. Mackiewicz, "Overview of iec 61850 and benefits," in Proc. $/ 2006$ IEEE PES Transmission and Distribution Conf. and Exhibition, 2006, pp. 376-383.

[16] H. Frank, S. Mesentean, and F. Kupzog, "Simplified application of the iec 61850 for distributed energy resources," in Computational Intelligence, Communication Systems and Networks, 2009. CICSYN '09. First International Conference on, 23-25 2009, pp. 172 -177.

[17] A. Ruiz-Alvarez, A. Colet-Subirachs, O. Gomis-Bellmunt, F. AlvarezCuevas-Figuerola, and A. Sudria-Andreu, "Design, management and comissioning of a utility connected microgrid based on iec 61850," June 2010, iEEE ISGT Europe 2010, Gothenburg, Sweden, October 11-13, 2010. 